\title{
Pine Cone Biorefinery: Integral Valorization of Residual Biomass into Lignocellulose Nanofibrils (LCNF)-Reinforced Composites for Packaging
}

\author{
Jon Trifol, Diana Catalina Marin Quintero, and Rosana Moriana*
}

Cite This: ACS Sustainable Chem. Eng. 2021, 9, 2180-2190

Read Online

ACCESS | Lل山l Metrics \& More | 回 Article Recommendations | st Supporting Information

ABSTRACT: Presented herein is the integral valorization of residual biomass to film composites by their fractionation into building blocks in a multicomponent cascade isolation approach. First, pine cones were subjected to alkaline pretreatment, followed by soda pulping. Two different hemicellulose/ligninbased fractions were recovered from the extractives of these treatments, with a yield of $19 \%$. Then, chloride- and peroxide-based bleaching methods were proposed to treat the soda-pulped samples, obtaining two cellulose-rich fractions with different chemical compositions and recovery yields (32\% and 44\%, respectively). From these cellulose fractions, two types of nanocelluloses with different lignin contents were obtained: cellulose nanofibrils (CNF), with a lignin content of $1 \%$, and lignocellulose nanofibrils (LCNF), with a lignin content of $16 \%$. The LCNF displayed lower crystallinity and viscosity but greater diameter and thermal stability than the CNF. The reinforcing capability of different amounts of both nanocelluloses on the first hemicellulose/lignin-based fraction (PCA-L) to

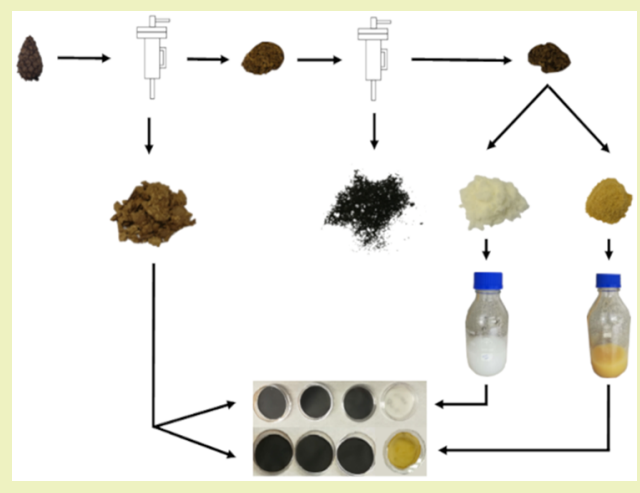
form films was evaluated. The thermomechanical, barrier, antioxidant, moisture sorption, and mechanical properties were assessed and compared. In general, the LCNF films showed less moisture sorption and better thermomechanical and antioxidant properties than the CNF films. These results reveal LCNF to be a promising reinforcing agent for designing all-lignocellulose-based composite films to be used in food packaging applications.

KEYWORDS: Biomass integral fractionization, Nanocelluloses, Biobased nanocomposites, Gas barrier properties, Thermomechanical properties, Food packaging films

\section{INTRODUCTION}

A biorefinery is an array of processes where lignocellulosic biomass may be fractionated and converted into high-valueadded products. ${ }^{1-8}$ In Europe, the forest is the most abundant biomass feedstock, with approximately 182 million hectares of forest, ${ }^{9}$ which generate a turnover of more than 486 billion euros. Pines are one of the most common trees in forests, being the Scots pine the most abundant species in European forests. ${ }^{10}$ The exploitation of forestland to obtain timber stock produces high amounts of logging residues that are often left in the mountains, resulting in a negative environmental impact and risk of wildfire. ${ }^{11}$ A sustainable waste management approach may be to convert this low-value-added residual biomass into valuable materials. In previous studies, pine needles, pine cones, branches, bark, and chips were proposed as raw materials to produce cellulose fibers and nanocelluloses. ${ }^{12-14}$ Cashew tree residues were used as a source of bacterial cellulose. ${ }^{15}$ Hardwood bark was the proposed raw material to isolate suberin and synthesize a polyepoxy acid-based hydrophobic coating. ${ }^{9-11}$ Softwood bark was valorized into nanocellulosereinforced polysaccharide-based nanocomposites. ${ }^{16}$ Galactoglucomannan-lignin networks isolated from chemothermome- chanical pulping side streams were used together with cellulose nanofibrils (CNF) to form composites. ${ }^{17}$

CNF have been widely proposed to be applied in food packaging $^{18-21}$ not only due to their good oxygen barrier properties but also because they are biobased, biodegradable, and transparent and exhibit unique mechanical properties. ${ }^{19}$ Traditionally, CNF have been isolated from different versions of bleached pulp, but recently, unbleached pulps ${ }^{24-27}$ have also been used to isolate CNF-containing lignin (lignocellulose nanofibrils, LCNF). The use of LCNF instead of CNF in packaging may potentially offer new funtionalities to the products because lignin has shown antioxidant, ${ }^{22}$ UV-blocking, ${ }^{23}$ and antimicrobial ${ }^{24}$ properties, among others. Different nanocomposites designed from $\mathrm{CNF}$ and other wood

Received: October 20, 2020

Revised: January 10, 2021

Published: January 29, 2021 


\section{PINE CONE}

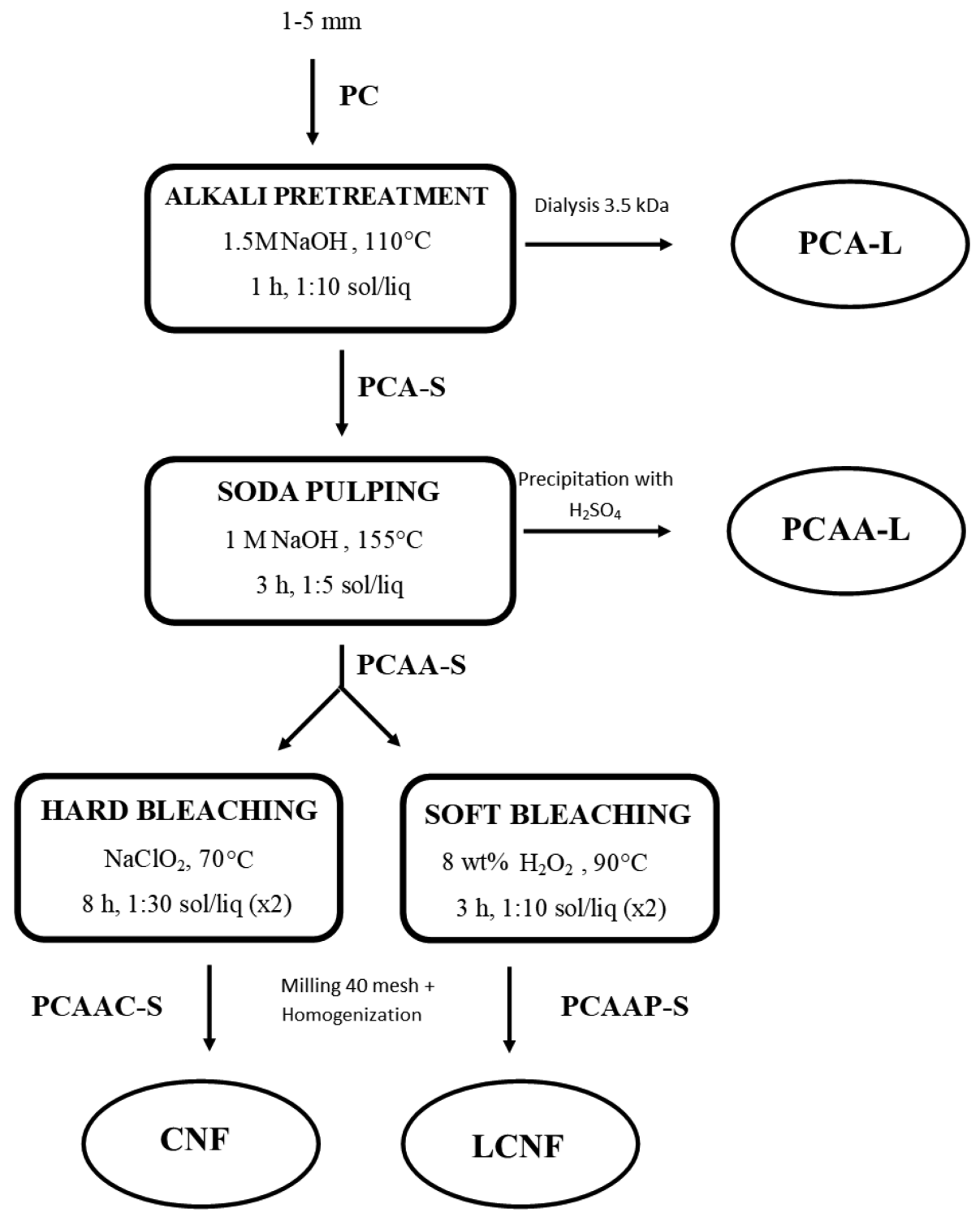

Figure 1. Biorefinery cascade process for the sequential recovery of hemicellulose/lignin-based (PCA-L and PCAA-L) and cellulose-based (PCAAC-S and PCAAP-S) fractions and cellulose nanofibrils (CNF and LCNF).

components (lignin, hemicelluloses, pectins, etc.) ${ }^{25-29}$ have been formulated. However, despite the attractive properties that lignin and LCNF can offer together due to their chemical affinity, the use of LCNF as a reinforcement of lignin matrix composite films is still unexplored.

Here, for the first time, an integral fractionation of residual biomass is presented by means of a multicomponent cascade recovery approach to obtain hemicellulose/lignin-based fractions and nanocelluloses that will be valorized into multifunctional films. Among the different logging residues, pine cones were chosen as the raw material to be fractionated due to its vast availability as a forest residue (pines can produce annually 180$100 \mathrm{~kg}$ of pine cones per hectarea ${ }^{30}$ ) and as an agro-food residue from the pine nut industry with a yearly estimated production of around 27 thousand tones. ${ }^{31}$ The scope of this paper includes (i) developing a sequential isolation approach to fractionate the pine cones almost integrally into hemicellulose/lignin and cellulose-rich fractions, (ii) isolating CNF and LCNF from the cellulose-rich fractions and studying the influence of their lignin content on the nanocellulose processing and film-forming ability, and (iii) correlating the influence of the content of nanocellulose lignin with the performance of different hemicellulose/lignin-based films in terms of thermomechanical, barrier, and moisture-resistance properties.

\section{EXPERIMENTAL SECTION}

Materials and Chemicals. Pine cones were collected from a pine forest (Pinus sylvestris) (Stockholm, Sweden) and conditioned at $40^{\circ} \mathrm{C}$ for 1 week. They were ground in a mill (Moretto granulator, Universalmuehle GR18/10M1A, Germany) to $2-5 \mathrm{~mm}$ to ensure their impregnation with the cooking liquids during the alkaline processes and, therefore, the effectivity of all the chemical steps within the biorefinery processes. All chemicals were used as received without further purification: 30 vol $\% \mathrm{H}_{2} \mathrm{O}_{2}$ solution (CAS No. 7722-84-1, Merck), $\mathrm{H}_{2} \mathrm{SO}_{4}$ (72 vol \%, LabService $\mathrm{AB}$, Sweden), $\mathrm{NaOH}(98 \%$, reagent grade, Sigma-Aldrich), $\mathrm{NaClO}_{2}$ (puriss $80 \%$, Sigma-Aldrich), and acetic acid (ACS reagent $>99.8 \%$ ). L-(+)-Arabinose (99.9\%, CAS No. 5328-37-0), D-(+)-galactose (99.9\%, CAS No. 59-23-4), D(+)-glucose (99\%, CAS No. 50-99-7), D-(+)-xylose (99\%, CAS No. 
58-86-6), D-(+)-mannose (99\%, CAS No. 3458-28-4), L-rhamnose monohydrate (99\%, CAS No. 6155-35-7), D(+)-galacturonic acid monohydrate (97\%, CAS No. 91510-62-2), and D-glucuronic acid (98\%, CAS No. 6556-12-3) were used as sugar references.

Biorefinery Process. An integral fractionation of pine cones is proposed by the implementation of a cascade multicomponent isolation approach (Figure 1) consisting of the following.

Alkali Pretreatment. Alkali pretreatment was performed as reported previously elsewhere with two objectives to open up the cell wall structures to enhance the isolation of the cellulosic fibers in the following chemical steps and to recover the extracted amorphous cell wall components from the liquid fraction (hemicelluloses and lignin) generated during this pretreatment. ${ }^{4,32}$ First, $100 \mathrm{~g}$ of PC was added to $1 \mathrm{~L}$ of $1.5 \mathrm{M} \mathrm{NaOH}$ in an autoclave inside a glycol bath at $110^{\circ} \mathrm{C}$ for $1 \mathrm{~h}$. Thereafter, the alkaline suspension was washed with Milli- $\mathrm{Q}$ water to obtain a solid fraction (PCA-S). The liquid phase was further purified by using a $3.5 \mathrm{kDa}$ membrane before being freeze-dried (PCA-L).

Soda Pulping. The PCA-S fraction was treated with a solution of 1 $\mathrm{M} \mathrm{NaOH}$ in a 1:5 solid-to-liquid ratio at $155^{\circ} \mathrm{C}$ for $3 \mathrm{~h}$. The resulting suspension was washed by filtration, and the solid (PCAA-S) and liquid phases were separated. The liquid phase was heated to $60^{\circ} \mathrm{C}$ under magnetic stirring and acidified ( $\mathrm{pH} 2$ ) via dropwise addition of $64 \mathrm{wt} \%$ $\mathrm{H}_{2} \mathrm{SO}_{4}{ }^{33}$ Then, the solution was kept under magnetic stirring for 30 $\mathrm{min}$ and cooled via an ice bath. Finally, the suspension was centrifuged at $3000 \mathrm{rpm}$ for $5 \mathrm{~min}$ to recover the sedimented fraction (PCAA-L).

Bleaching Treatment. The PCAA-S fraction was divided 50-50, and every part was submitted to two parallel procedures.

(i) Peroxide-based bleaching: First, $10 \mathrm{~g}$ of dried PCAA-S was bleached with a solution of $8 \mathrm{wt} \% \mathrm{H}_{2} \mathrm{O}_{2}(100 \mathrm{~mL}$ of liquid in total) at $\mathrm{pH} \approx 11-12$ at $90{ }^{\circ} \mathrm{C}$. The process was performed in two steps of $3 \mathrm{~h}$ each. The insoluble sample was filtered and cleaned with deionized water (PCAAP-S).

(ii) Chloride-based bleaching: First, $10 \mathrm{~g}$ of dried PCAA-S was added to $320 \mathrm{~mL}$ of Milli-Q water and then heated to $70{ }^{\circ} \mathrm{C}$. Then, $2 \mathrm{~mL}$ of acetic acid and $9.2 \mathrm{~mL}$ of a solution of $25 \mathrm{wt} \%$ $\mathrm{NaClO}_{2}$ were added every hour for the next $8 \mathrm{~h} .{ }^{34}$ Finally, the insoluble sample was filtered and cleaned with deionized water (PCAAC-S).

Nanocellulose Isolation. The bleached fractions (PCAAP-S and PCAAC-S) were dried and milled to 20 mesh in a Wiley mill. A $1 \mathrm{wt} \%$ suspension in Milli- $Q$ water was achieved by vigorous stirring of the solid material for $2 \mathrm{~h}$. Then, the suspension was passed through a homogenizer M110EH Microfluidic processor (Microfluidics, Westwood, Massachusetts, USA). In the first pass, the suspension went through $400 / 200 \mu \mathrm{m}$ chambers in series at a pressure of $650 \mathrm{bar}$; thereafter, it was passed four times through $200 / 100 \mu \mathrm{m}$ chambers at a pressure of $1650 \mathrm{bar}$. The solutions were stored at $4{ }^{\circ} \mathrm{C}$ and coded as LCNF and CNF, respectively.

Preparation of Nanocomposite Films. Two different sets of composites were produced by film casting using the PCA-L fraction as the polymeric matrix and different concentrations $(30 \%, 45 \%$, and $60 \%$ ) of both nanocelluloses (LCNF and CNF) as reinforcement systems. The PCA-L fraction and the different composite formulations were dispersed homogeneously in water at $40{ }^{\circ} \mathrm{C}$ under magnetic stirring during $2 \mathrm{~h}$. Thereafter, the suspenions were ultrasonicated for 15 min to be finally cast and dried at room temperature during 7 days. The solid concentration of the final suspension was approximately 0.4 wt $\%$, resulting in a grammage of $0.012 \mathrm{~g} / \mathrm{cm}^{2}$. The thickness of the prepared films were around $80 \mu \mathrm{m}$ for the CNF formulations and 100 $\mu \mathrm{m}$ for the LCNF films with a typical standard deviation of $5 \mu \mathrm{m}$ for both types of nanocelluloses.

Characterization of Biorefinery Fractions and Biobased Composite Films. Chemical Composition. The total amount of soluble extractives in water and ethanol of the PC was determined by Soxhlet extraction, as reported in Garcia-Garcia et al. ${ }^{14}$ The TAPPI test method T222 om-06 (TAPPI, 2006) was followed to calculate the Klason lignin content. The carbohydrate composition was evaluated by conventional two-step Saeman hydrolysis, followed by quantification of the released monosaccharides using high-pH anion-exchange chroma- tography with pulsed amperometric detection (HPAEC-PAD, Dionex ICS-3000, Thermo Fisher Scientific, Sunnyvale, California, USA). The ash content of each sample was determined by thermogravimetric analysis in a Mettler Toledo TGA/DSC 1 STAR (Mettler Toledo, Columbus, Ohio, USA) system following a previously published method. ${ }^{35}$

Gravimetry Yield. The gravimetric yield of each step within the biorefinery process was calculated by measuring the dry mass of the samples before and after each chemical step.

Scanning Electron Microscopy (SEM). A Hitachi S-4800 (Hitachi, Tokio, Japan) field emission scanning electron microscope at $5 \mathrm{kV}$ was used to assess the isolation of the cellulose fibers. Samples were sputtercoated with a $2.5 \mathrm{~nm}$ thick layer.

Fourier Transform Infrared (FTIR) Spectroscopy. The samples were analyzed in triplicate by FTIR spectroscopy (FTIR, PerkinElmer Spectrum 100 FTIR, PerkinElmer, Waltham, Massachusetts, USA), (ATR, Golden Gate from Graseby Specac LDT, Kent, England) at 4.0 $\mathrm{cm}^{-1}$ resolution in a range of $850-4000 \mathrm{~cm}^{-1}$, calculated as the average of 16 individual scans. The crystallinity index $(\mathrm{CrI})$ of the cellulose was calculated as estimated by Nelson and O'Connor ${ }^{36}$ (eq 1), where $H_{1371}$ is the height of the peak at $1371 \mathrm{~cm}^{-1}$, and $H_{2900}$ is the height of the peak at $2900 \mathrm{~cm}^{-1}$.

$$
\mathrm{CrI}=\frac{H_{1371}}{H_{2900}}
$$

Thermogravimetric Analysis (TGA). The thermal behavior of the samples was evaluated by TGA in an inert atmosphere. Each dried sample (3-5 mg) was pyrolyzed from 25 to $800{ }^{\circ} \mathrm{C}$ at $10^{\circ} \mathrm{C} / \mathrm{min}$ with $\mathrm{N}_{2}(50 \mathrm{~mL} / \mathrm{min})$ in a Mettler Toledo TGA/DSC 1 STAR system (Mettler Toledo, Columbus, Ohio, USA).

$X$-ray Diffraction (XRD). XRD patterns were obtained by using a Bruker CCD-Apex (Bruker, Billerica, Massachusetts, USA) apparatus equipped with an $\mathrm{X}$-ray generator (Ni-filtered $\mathrm{Cu} \mathrm{K} \alpha$ radiation). The instrument was operated at $40 \mathrm{kV}$ and $40 \mathrm{~mA}$ in a $2 \theta$ range of $5^{\circ}-40^{\circ}$ with a $0.06^{\circ}$ step. The crystalline index $(\mathrm{CI})$ was estimated by using the empirical method proposed by Segal et al. ${ }^{37}$ (eq 2)

$$
\mathrm{CI}=\frac{I_{200}-I_{\mathrm{am}}}{I_{200}} \times 100
$$

where $I_{200}$ corresponds to the maximum intensity of the reflection plane 200 (approximately $2 \theta=22^{\circ}$ ), and $I_{\text {am }}$ corresponds to the minimum intensity of the amorphous part of the sample (approximately $2 \theta=$ $\left.18^{\circ}\right)$.

Size Exclusion Chromatography (SEC). An SEC 1260 Infinity system (Polymer Standard Services, Germany) was used to determine the molecular weight distributions of the lignin-based fractions. Five milligrams of each sample was dissolved in a solution of $2 \mathrm{~mL}$ of DMSO $+0.5 \% \mathrm{LiBr}(\mathrm{w} / \mathrm{w})$, which was thereafter filtered through a $0.45 \mathrm{~mm}$ PTFE membrane. ${ }^{38}$

Transmission Electron Microscopy (TEM). TEM images were obtained to analyze the morphology of the nanocelluloses with a Hitachi T7700 (Hitachi, Tokio, Japan) system at $100 \mathrm{kV}$. A drop of a 0.05 wt $\%$ suspension was cast in a carbon-Formvar grid that was dried at room temperature for at least $2 \mathrm{~h}$ before being inserted into the TEM instrument.

Viscosity. The viscosity of a $0.9 \mathrm{wt} \%$ suspension of nanocelluloses was investigated in a Discovery DHR-2 rheometer (TA Instruments, New Castle, Delaware, USA) with a $60 \mathrm{~mm}$ diameter aluminum platecone geometry at $25^{\circ} \mathrm{C}$.

Moisture Uptake. Two films of $50 \mathrm{mg}$ for each sample were preconditioned at $23{ }^{\circ} \mathrm{C}$ and $50 \% \mathrm{RH}$ overnight before being weighed. Afterward, the samples were dried at $105{ }^{\circ} \mathrm{C}$ overnight and weighed again. The difference between these two weights divided by the dry weight of the material was defined as the moisture uptake. ${ }^{34}$

Tensile Properties. The tensile strength, strain, and modulus of each film were measured in an Instron Universal Testing Machine Model 5944 (Instron Engineering Corporation, Norwood, Massachusetts, USA) equipped with pneumatic jaws and a $250 \mathrm{~N}$ load cell. Five specimens $(5 \mathrm{~mm} \times 50 \mathrm{~mm})$ of each preconditioned film were tested 
A
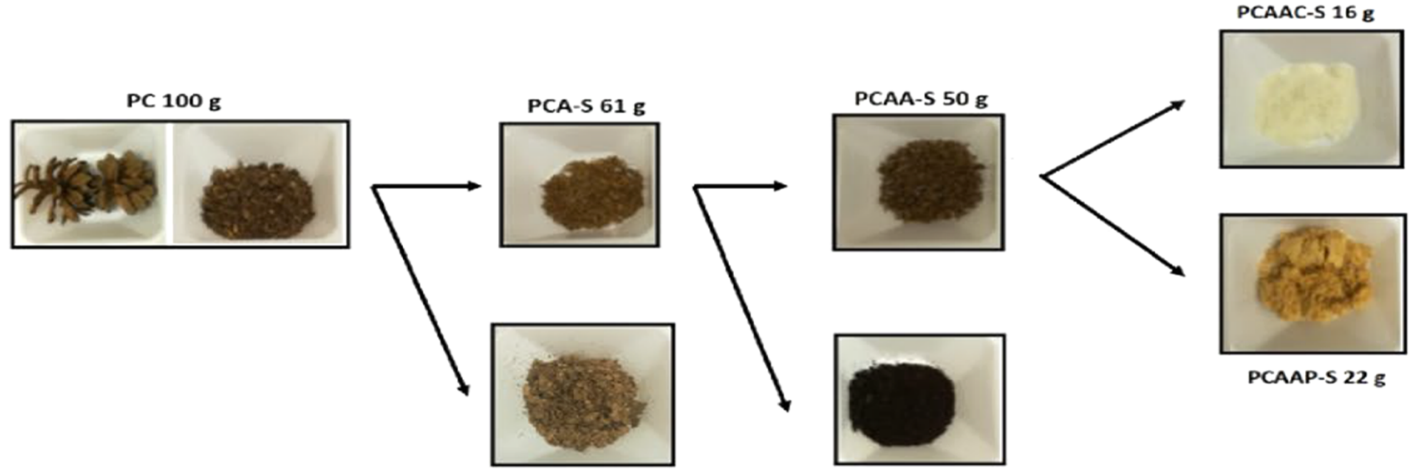

PCA-L $13 \mathrm{~g}$

PCAA-L $6 \mathrm{~g}$

B

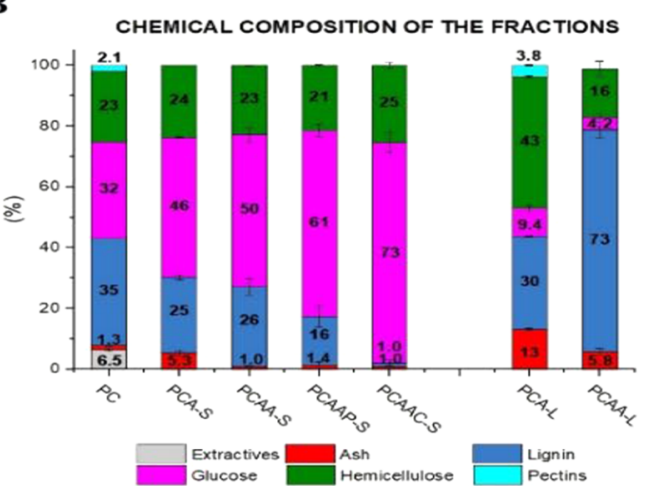

D

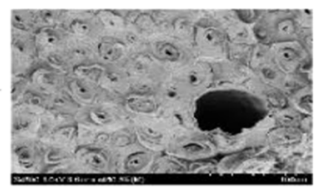

H

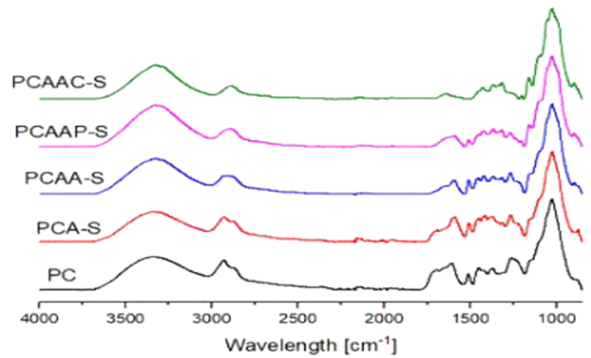

$\mathbf{J}$

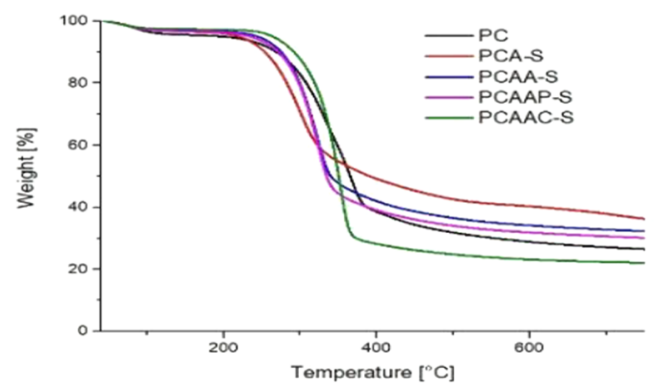

C

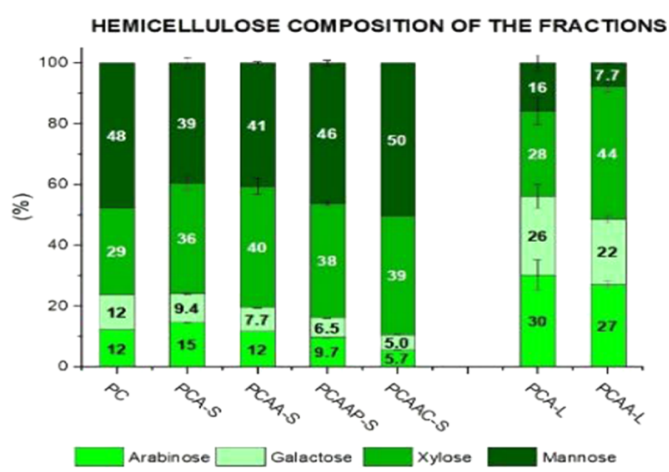

F
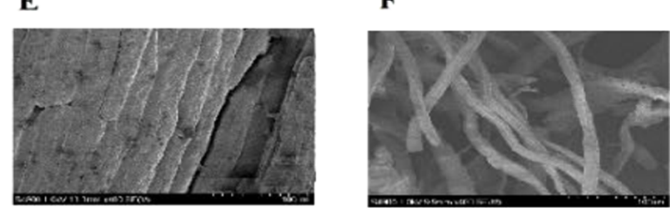

G

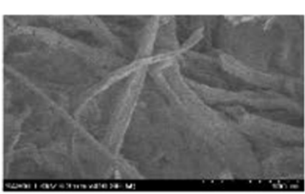

I

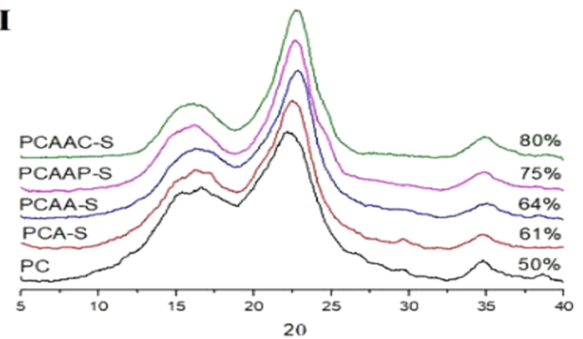

$\mathbf{K}$

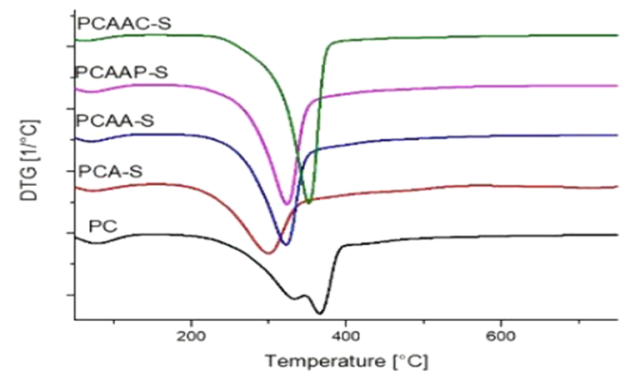

Figure 2. Biorefinery process to recover hemicellulose/lignin- and cellulose-based fractions and characterization of the solid biorefinery fractions. (A) Schematic representation of the bioprocess including recovery yields after each chemical treatment. (B) Chemical composition of the fractions in terms of glucose, lignin, pectins (galacturonic acid ${ }^{41}$ ), hemicelluloses, ash, and extractives. (C) Hemicellulose monosaccharide composition of the different fractions. (D-G) Scanning electron micrographs of (D) PC cross section, (E) PC surface, (F) PCAAP-S, and (G) PCAAC-S. (H) FTIR spectra of the biorefinery fractions. (I) XRD patterns of the fractions. (J) TG and (K) DTG curves of the biorefinery fractions. 
with an initial distance between the grips of $20 \mathrm{~mm}$ and a strain rate of the grips of $2 \mathrm{~mm} / \mathrm{min}$.

Oxygen Permeability. The oxygen transmission rate (OTR) (normalized to a $100 \mu \mathrm{m}$ film) of the films at $23{ }^{\circ} \mathrm{C}$ and $50 \% \mathrm{RH}$ was determined using a MOCON OX-TRAN TWIN system (Modern Controls, Inc., New Castle, Minnesota, USA) following the ASTM standard D3985-8 (ASTM 2005). The obtained OTR values were normalized to a $100 \mu \mathrm{m}$ film by multiplying the OTR value by the thickness of each film ${ }^{20}$ (to obtain the values in $\mathrm{mL} \mu \mathrm{m} \mathrm{m}^{2}$ day $^{-1}$ so the influence of the thickness is disregarded) and then dividing it by 100 to obtain the OTR values of a $100 \mu \mathrm{m}$ film, ${ }^{39}$ which is close to the average thickness of the films in this work.

Water Vapor Transmission Rate (WVTR). The WVTR (normalized to a $100 \mu \mathrm{m}$ film) of the films was measured in triplicate according to the norm NF $\mathrm{H} 00-03022$ at $23{ }^{\circ} \mathrm{C}$ and $50 \% \mathrm{RH}$, using calcium chloride as the desiccating agent and a cross section of $5 \mathrm{~cm}^{2}(\mathrm{~S})$. The mass increase of the cups was plotted against time, with slope $n$. The obtained WVTR values (in $\mathrm{g} \mu \mathrm{m} \mathrm{m}^{-2} \mathrm{day}^{-1}$ ) were normalized to a $100 \mu \mathrm{m}$ films by multiplying the WTVR value by the thickness of each film ${ }^{20}$ and dividing it by $100^{39}$ to disregard any film thickness influence.

$$
\mathrm{WVTR}=n \times \frac{1}{S}
$$

Antioxidant Properties. The antioxidant properties were investigated in duplicate by DSC (Mettler Toledo, Columbus, Ohio, USA) in an oxidative atmosphere as reported elsewhere. ${ }^{40}$ Briefly, approximately $3 \mathrm{mg}$ of each film was placed in a DSC crucible and heated from 30 to $350{ }^{\circ} \mathrm{C}$ at $5{ }^{\circ} \mathrm{C} /$ min under an oxygen atmosphere $(250 \mathrm{~mL} / \mathrm{min})$.

\section{RESULTS AND DISCUSSION}

The different fractions obtained from the alkali, soda, and bleaching treatments biorefinery process (Figure 1) are displayed in Figure 2A. The overall gravimetric yield after each treatment and chemical composition of each biorefinery product are detailed in Figure 2A-C. The PC chemical composition was in the range of what has been reported in the literature. ${ }^{14,42-44}$ During the alkali pretreatment, almost $40 \%$ of the initial mass was lost due to the removal of extractives, lignin, and pectins. The obtained solid fraction after the pretreatment (PCA-S) displayed the same amount of hemicelluloses in their composition as the PC (23\%). However, 9\% less mannose was reported in PCA-S than in PC, indicating that mannose was the most abundant hemicellulosic monosaccharide extracted during alkalinization, although no large amounts of mannose were found in the liquid extract. This fact indicated that the alkaline pretreatment degraded the mannose, and the resulting degraded products were lost during the dialysis. ${ }^{45}$ The lignin recovered in the PCA-L fraction was $11.5 \%$ of the initial lignin content in the $\mathrm{PC}$, with a molecular weight of $\mathrm{Mn}=1714 \mathrm{~g} / \mathrm{mol}, \mathrm{Mw}=2174 \mathrm{~g} /$ mol, and PDI $=1.26$. After the alkaline pretreatment, the PCA-S fraction was submitted to a soda pulping process, losing $18 \%$ of its mass and resulting in a sample (PCAA-S) with a lignin and hemicellulose content similar to that of the PCA-S fraction. The liquid fraction was acidified, and $12 \%$ of the initial PCA-S was recovered as a lignin-rich fraction (PCAA-L), with 73\% lignin in its composition. The molecular weight of this lignin resulted in values of $\mathrm{Mn}=4025 \mathrm{~g} / \mathrm{mol}, \mathrm{Mw}=11740 \mathrm{~g} / \mathrm{mol}$, and PDI $=2.92$, which are in line with other reports in the literature. ${ }^{46,47}$

The PCAA-S sample was divided into two equal parts and subjected to two different bleaching processes in order to obtain two different cellulosic-rich fractions with and without lignin in their composition. Bleaching with peroxide led to a sample where lignin was partially removed. However, the attempts to use peroxide to completely remove lignin from the pulp failed, and a sodium chlorite-based bleaching was proposed as a hardest bleaching treatment. Bleaching with chlorite led to a sample (PCAAP-S) with $16 \%$ of lignin, whereas after bleaching with peroxide (PCAAC-S), only $1 \%$ of lignin was kept in the samples. Therefore, the higher purity of PCAAC-S resulted in a greater mass loss during the chlorite-based bleaching than that after bleaching with peroxide. In total, $38 \mathrm{~g}$ of cellulose-based fractions was recovered (16 $\mathrm{g}$ of PCAC-S and $22 \mathrm{~g}$ of PCAAP-S), which led to a $76 \%$ recovery yield of the PCAA-S.

The fractions obtained after each chemical treatment were physicochemically characterized. The change in the morphology was followed by SEM micrographs (Figure 2D, E). The cross section (Figure 2D) shows aligned fiber bundles bonded together by amorphous components (such as pectins, lignin, and hemicelluloses). Figure $2 \mathrm{E}$ reveals a large-pore-based inner part stiffened by alignment of the sclerenchyma fibrous section. ${ }^{48}$ The removal of the amorphous components as the biorefinery process progressed enabled the fiber bundles to be individualized into fibers with similar diameters (approximately $14 \mu \mathrm{m}$ ) for both fractions, PCAAC-S (Figure 2F) and PCAAP-S (Figure $2 \mathrm{G}$ ). This diameter is similar to that reported for bast fibers (i.e., jute, cotton, or flax), smaller than that of sisal or coir fibers, ${ }^{49}$ slightly smaller than that of fibers from pine wood (which are approximately $30 \mu \mathrm{m}$ ), ${ }^{50}$ and smaller than that of fibers from hardwoods such as Cordia goeldiana and Brosimun parinarioides (above $100 \mu \mathrm{m}$ ). ${ }^{51}$

The FTIR spectra in Figure $2 \mathrm{H}$ show the progressive removal of the amorphous components after each chemical treatment. The $\mathrm{OH}$ stretching band at $3300 \mathrm{~cm}^{-1}$ corresponding to the aliphatic moieties in polysaccharides became narrower in the bleached samples due to the removal of part of the amorphous components, as reported by Garcia-Garcia. ${ }^{14}$ Despite retaining the same amounts of hemicelluloses during the pretreatment and soda pulping, the peak at $1720 \mathrm{~cm}^{-1}$ related to the $\mathrm{C}=\mathrm{O}$ vibrations in carboxylic acids and acetyl and methyl ester groups associated with the lateral branches of the hemicelluloses ${ }^{4}$ and/ or related to the lignin-carbohydrate complex bonds of hemicelluloses ${ }^{52}$ disappeared in the PCAA-S spectra. These results suggested that soda pulping debranched the hemicelluloses, probably via alkaline hydrolysis, ${ }^{53}$ unlike pretreatment. Finally, the intensities of the lignin-related peaks at 1595, 1512 , and $1462 \mathrm{~cm}^{-154}$ were significantly reduced after the bleaching treatments, especially in the PCAAC-S sample, due to the strongest delignification that was performed. The crystallinity index ( $\mathrm{CrI})$ of the cellulose for all the samples was estimated by FTIR spectroscopy. An increase in the CrI from 0.75 for the PC sample to 0.98 for the PCAA-S sample indicated that alkali treatments removed not only amorphous components but also amorphous cellulose. Chlorite bleaching increased the CrI to 1.09 , whereas peroxide bleaching did not affect this value, indicating that PCAAC-S has more crystalline cellulose than PCAAP-S.

Figure 2I shows the XRD patterns of the solid fractions, where the typical crystalline peaks of type I cellulose at $15^{\circ}-16^{\circ}$ and $22^{\circ}$ were detected. After both alkali treatments, these peaks became more defined due to the removal of the amorphous components, resulting in an increase in the CI from 50\% to $64 \%$. Higher CI values were obtained for the bleached samples; however, among them, PCAAP-S displayed the lowest value due to its lower cellulose crystallinity and higher lignin content.

Thermogravimetric (TG) and first-derivative thermogravimetric (DTG) curves for all the studied samples are shown in Figure $2 \mathrm{~J}$ and $\mathrm{K}$. Two main weight-loss regions were identified 


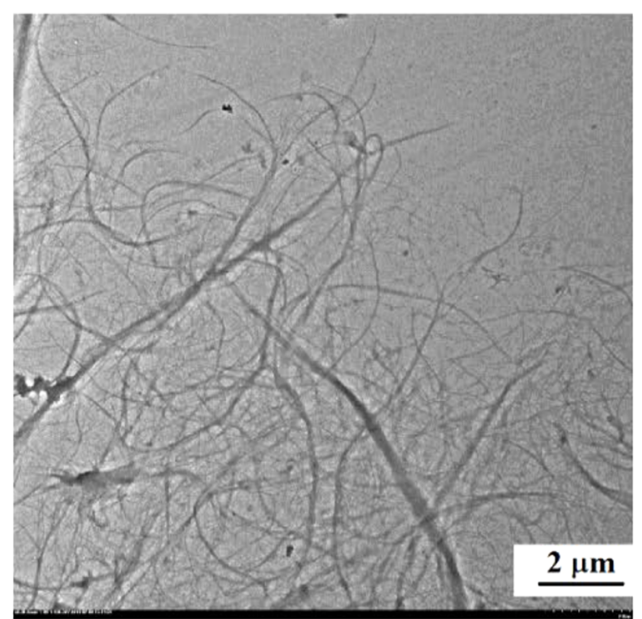

C

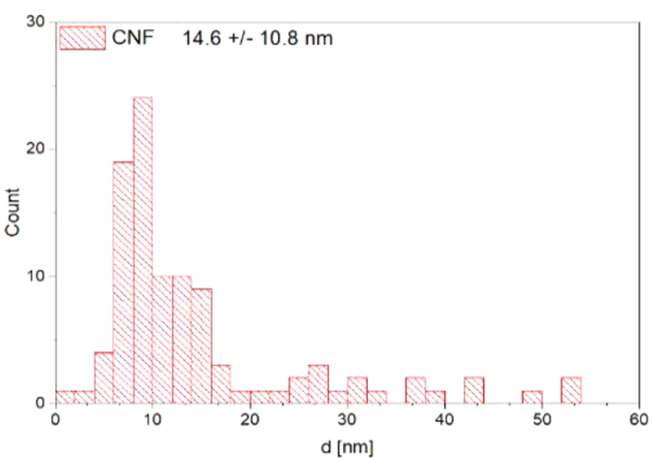

$\mathbf{E}$

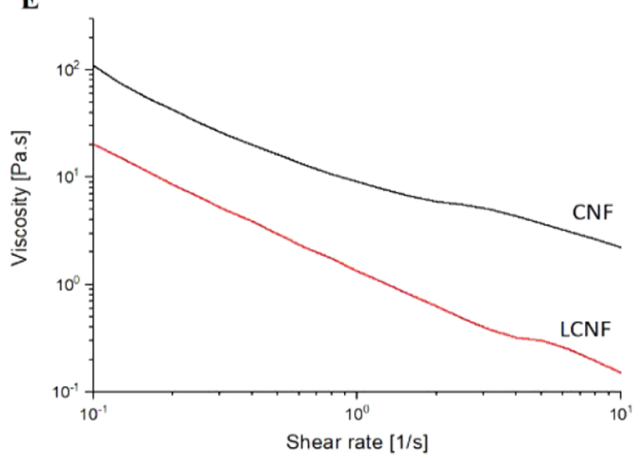

G

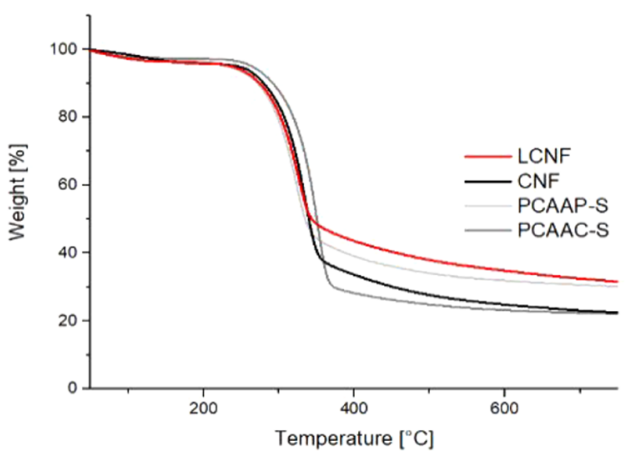

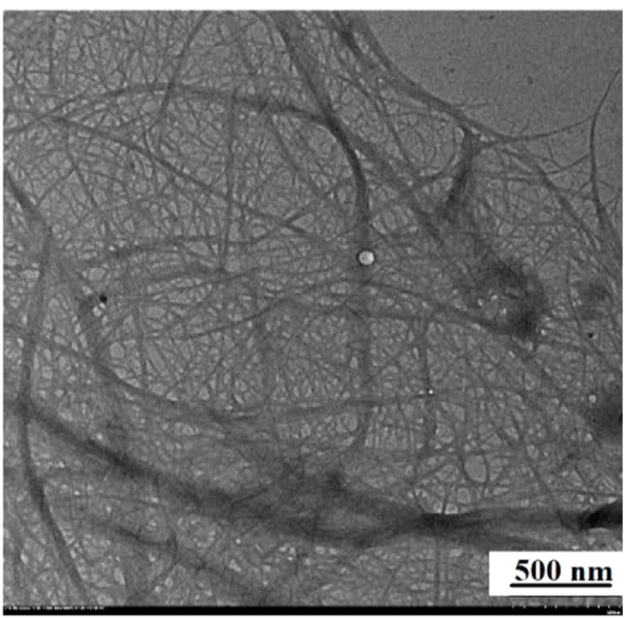

D

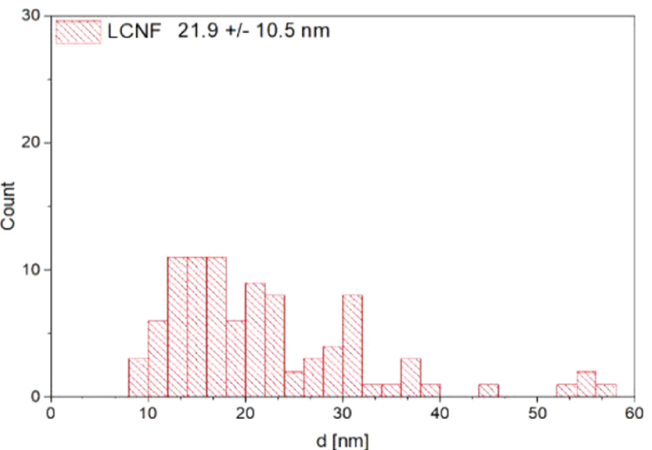

F

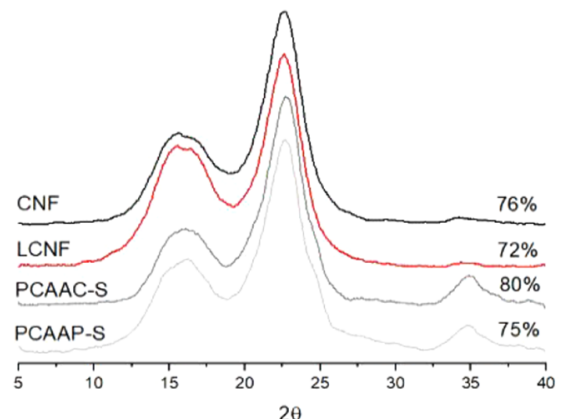

$\mathbf{H}$

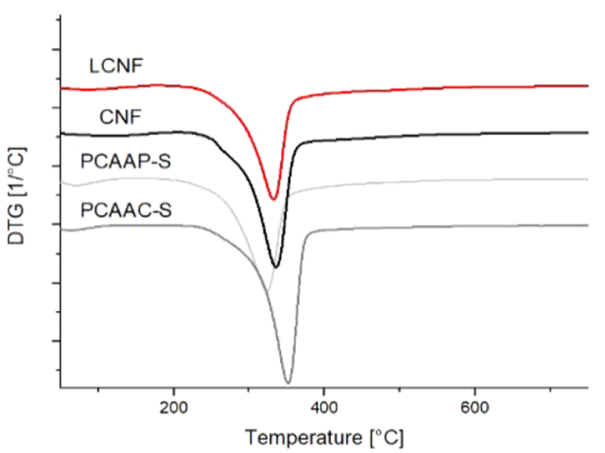

Figure 3. Physicochemical characterization of CNF and LCNF. (A, B) Transmission electron micrographs of CNF (A) and LCNF (B). (C, D) Size distribution of both nanocelluloses, CNF (C) and LCNF (D). (E) Rheological measurements of both nanocelluloses at $0.9 \mathrm{wt} \%$. (F) XRD patterns of nanocelluloses and their precursor pulp. (G) TG and (H) DTG curves of the nanocelluloses and their corresponding precursor pulp.

from these curves: a first weight loss $(<5 \%)$ at less than $150{ }^{\circ} \mathrm{C}$ related to moisture evaporation and a second region (150 and
$650{ }^{\circ} \mathrm{C}$ ) where three overlapping thermal processes centered at 333,365 , and $400{ }^{\circ} \mathrm{C}$ were related to the pyrolysis of 
A

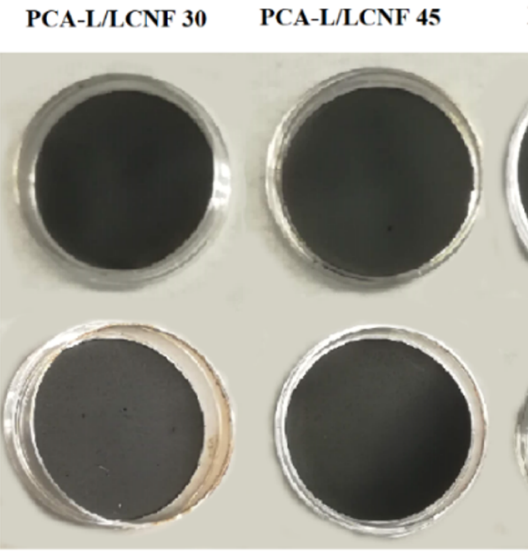

PCA-L/LCNF $60 \quad$ LCNF

PCA-L/CNF 30

PCA-L/CNF 45

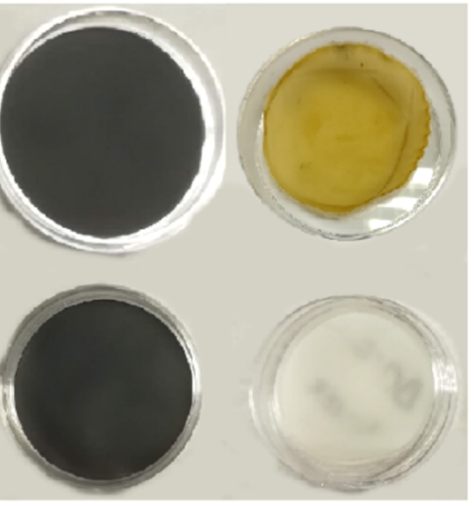

B
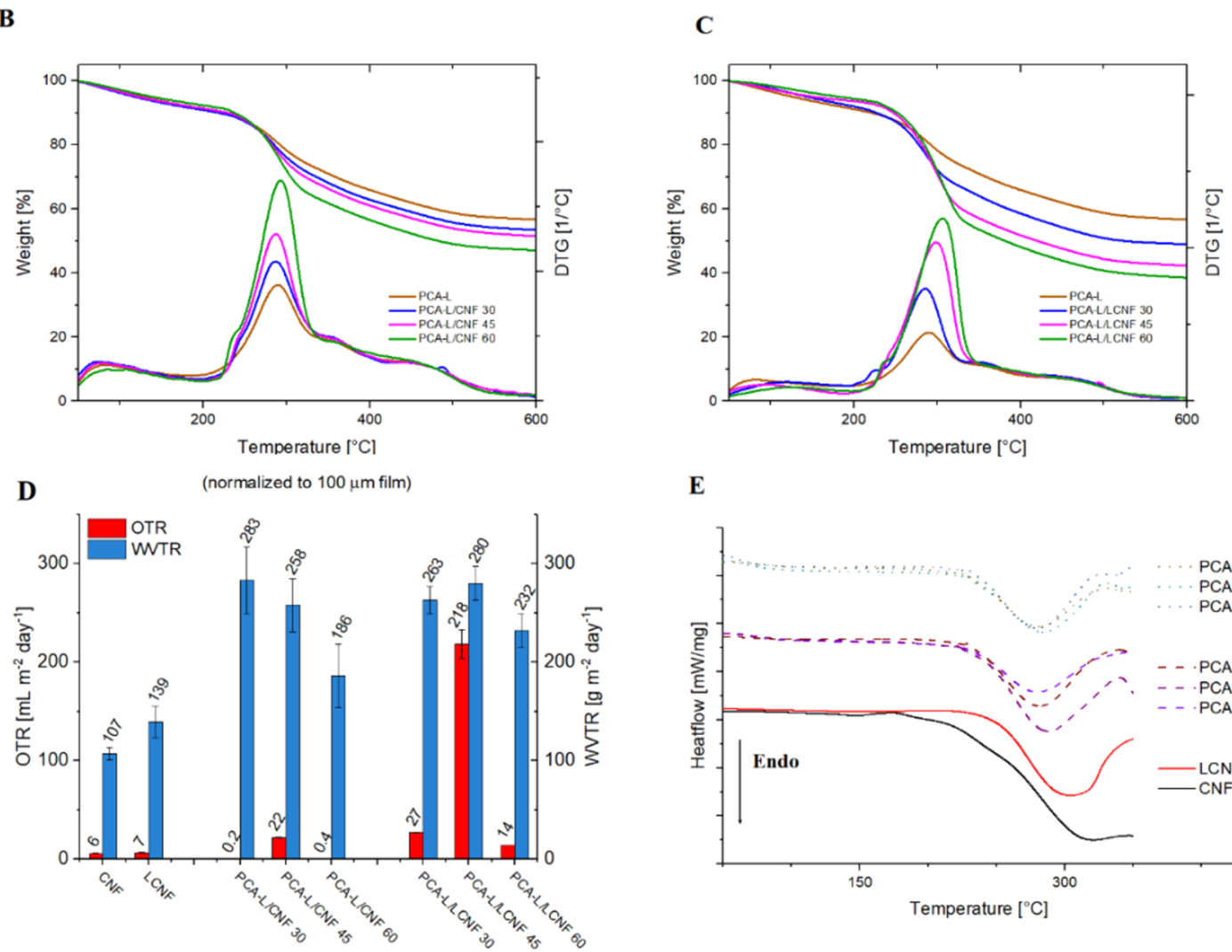

E

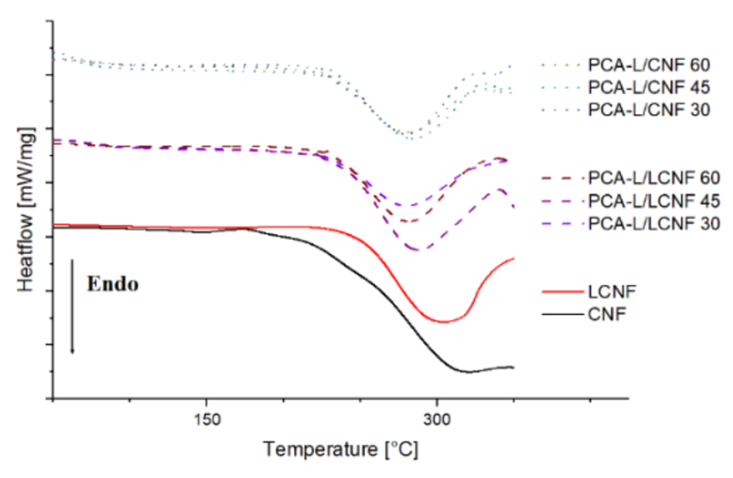

Figure 4. Characteristics of the nanocellulose-based films. (A) Visual appearance of the films. (B) TG and DTG curves of the CNF films. (C) TG and DTG curves of the LCNF films. (D) Water and oxygen transmission rate of the developed films (normalized to $100 \mu \mathrm{m}$ ). (E) DSC curves under an $\mathrm{O}_{2}$ atmosphere.

hemicellulose/pectin, cellulose, and lignin, respectively. The progressive removal of the amorphous components during the biorefinery process was observed in this second region, where after the alkaline and bleaching treatments only one well-defined and narrower peak related to the thermal decomposition of cellulose was clearly identified. The bleached samples degraded within a narrower temperature range and showed better thermal stability than the PC and alkali samples. This increase in the thermal stability is attributed to the increased crystallinity and proportion of intermolecular hydrogen-bonded domains after the extraction of the amorphous components. ${ }^{6}$ The highest efficiency of the chlorine bleaching process allowed us to obtain a more pure and crystalline cellulose sample, which resulted in an onset value $40{ }^{\circ} \mathrm{C}$ higher than that found for PCAAP-S (273 $\left.{ }^{\circ} \mathrm{C}\right)$.

Biorefinery Process: Cellulose Nanofibrils with Different Lignin Contents. PCAAC-S and PCAAC-P were used as raw materials to isolate cellulose nanofibrils with different lignin contents. The physicochemical properties of both nanocelluloses were evaluated and compared to those of their precursor pulp to understand the influence of the lignin content on the nanocellulose isolation process and on their quality. Specifically, cellulose nanofibrils with less than $1 \%$ lignin content were obtained from PCAAC-S (CNF), and cellulose nanofibrils with $16 \%$ lignin were isolated from PCAAC-P (LCNF). Figure $3 \mathrm{~A}$ and $\mathrm{B}$ reveals the coexistence of both individualized nanofibrils and microfibers for both types of nanocelluloses 
Table 1. Moisture Uptake and Summary of Tensile Properties of Materials ${ }^{a}$

$\begin{array}{lcccc} & \text { Moisture Uptake }(\%) & E(\mathrm{GPa}) & s(\%) & \sigma(\mathrm{MPa}) \\ \text { PCA-L/CNF 30 } & 12.0 \pm 0.7 & 4.72 \pm 0.42 & 0.95 \pm 0.44 & 33.5 \pm 12 \\ \text { PCA-L/CNF 45 } & 14.0 \pm 0.6 & 6.11 \pm 0.19 & 2.01 \pm 0.03 & 94.8 \pm 5.6 \\ \text { PCA-L/CNF 60 } & 10.8 \pm 0.6 & 4.38 \pm 0.35 & 1.84 \pm 0.20 & 61.8 \pm 2.3 \\ \text { CNF } & 8.4 \pm 0.2 & 6.92 \pm 0.03 & 1.58 \pm 0.19 & 78.3 \pm 5.2 \\ \text { PCA-L/LCNF 30 } & 10.6 \pm 0.5 & 3.94 \pm 0.21 & 0.88 \pm 0.12 & 30.4 \pm 5.4 \\ \text { PCA-L/LCNF 45 } & 13.1 \pm 0.4 & 6.60 \pm 0.46 & 2.89 \pm 0.42 & 127 \pm 3.5 \\ \text { PCA-L/LCNF 60 } & 9.4 \pm 0.5 & 3.93 \pm 0.65 & 2.66 \pm 0.48 & 81.8 \pm 15.8 \\ \text { LCNF } & 9.1 \pm 0.3 & 3.78 \pm 0.26 & 6.36 \pm 0.27 & 122 \pm 4.8\end{array}$

${ }^{a} E$ represents Young modulus. $s$ represents strain at break. $\sigma$ represents stress at break.

with a length on the microscale. The histograms in Figure 3C and $\mathrm{D}$ show the diameter distribution of both nanocelluloses. CNF and LCNF displayed a similar broad polydispersity; however, the CNF showed a substantially lower average diameter than the LCNF ( 14.6 vs $21.9 \mathrm{~nm}$ ), which is in line with other reports in the literature. ${ }^{55}$ This difference in the average diameter may be attributed to a higher fibrillation efficiency in the absence of lignin since the diameter of the cellulose fibers in both pulps was similar. ${ }^{56}$ However, it could also be possible that the higher content of lignin in the LCNFs increased the fiber diameter, as the lignin and hemicellulose recovered the nanofibrils. ${ }^{57,58}$ The viscosity of both types of nanocelluloses was also evaluated (Figure $3 \mathrm{E}$ ), showing that the CNF had a substantially higher viscosity than the LCNF. Chen et al. ${ }^{55}$ also observed a decrease in viscosity with increasing lignin content, which was attributed to the lignin preventing hydrogen bonding between nanofibrils, thereby inhibiting percolation.

In Figure S1, similar FTIR spectra for both nanocelluloses and pulps are shown. The CrI of both types of nanocelluloses was also calculated and compared. A decrease in the CrI from 1.09 to 0.89 for the CNFs and from 0.97 to 0.66 for the LCNF was observed. This result indicated that cellulose was degraded in both cases during mechanical disintegration and that it was more significant in the LCNF due to the higher lignin content. The intensities of the XRD patterns for the CNF and LCNF were slightly lower than those of their corresponding raw materials (PCAAC-S and PCAAP-S) (Figure 3F), suggesting that the homogenization process destroyed part of the crystalline structure, ${ }^{59}$ as mentioned in the FTIR results.

Figure $3 \mathrm{G}$ and $\mathrm{H}$ compares the thermogravimetric curves of CNF and LCNF with those curves obtained for PCAAC-S and PCAAP-S. The LCNF displayed an onset $\left(278{ }^{\circ} \mathrm{C}\right)$ similar to that of its corresponding pulp, whereas the CNF displayed an onset temperature decreased by $30{ }^{\circ} \mathrm{C},{ }^{60}$ which may be attributed to the degradation of the cellulose and hemicellulose present in the CNF during the mechanical disintegration. Comparing the nanocellulosic samples, the LCNF exhibited higher thermal stability than the CNF samples despite of their higher crystallinity. This fact may indicate that the hemicelluloses in the CNF samples resulted in more damage during the isolation of the nanocelluloses.

Evaluating Reinforcing Capabilities of CNF and LCNF in Composite Film Formation. As has been previously stated, ${ }^{17,61,62}$ nanocellulose unique properties may be used to reinforce other biopolymeric wood components to confer filmforming properties and competitive performance and functionality. Therefore, in this study, the potential of CNF and LCNF as reinforcing agents of PCA-L was evaluated based on their filmforming capability and film performance assessment.
Two different sets of composites were formulated using the PCA-L fraction as the polymeric matrix and three different concentrations $(30 \%, 45 \%$, and $60 \%)$ of each nanocellulose as the reinforcement system (Figure 4A). The film formation of PCA-L, CNF, and LCNF was also evaluated (Figure 4A). However, PCA-L did not show film-forming capability, and the film fragmented upon drying. The addition of CNF and LCNF to PCA-L prevented crack formation, and all the formulations resulted in brownish films with good cohesion. As the solid content of all the formulations were similar, the resulting grammage of all the dried samples was also similar (around $0.12 \mathrm{gr} / \mathrm{cm}^{2}$ ). However, the CNF-based films showed a thickness of around $80 \mu \mathrm{m}$, whereas the LCNF-based films displayed a higher thickness of around $100 \mu \mathrm{m}$. Therefore, the CNF-based films had higher density than the LCNF-based films, and this fact may be attributed to the lower diameter of the CNF.

The performance of both sets of films and their potential as packaging materials were assessed in terms of thermal properties, gas permeability, antioxidant behavior, moisture sorption, and mechanical properties.

Figure 4B and C compares the TG and DTG curves of both sets of films with the curves of PCA-L. The thermal stability of PCA-L $\left(\sim 205{ }^{\circ} \mathrm{C}\right)$ increased as a function of the amount of nanocellulose in the formulations of both sets of films, which was more significant for the LCNF films. Among these films, the composite with a loading of $60 \%$ displayed the highest thermal stability, with an onset value of $240{ }^{\circ} \mathrm{C}$. The higher lignin content in the LCNF may result in an improvement of the compatibility between the matrix and the reinforcement, enhancing the interactions and therefore the thermal stability.

Figure $4 \mathrm{D}$ summarizes the oxygen transmission rate and water vapor transmission rate (OTR and WVTR, respectively) of all the developed films. Compared to the LCNF films, the CNF films showed better oxygen barrier properties and similar water vapor barrier properties, which is speculated to be due to the higher diameter and lower crystallinity of the LCNF samples, as biopolymers exhibit increased barrier properties with increasing crystallinity. ${ }^{63}$ The two sets of composites made from PCA-L and the two different types of nanocelluloses displayed lower WVTR than their corresponding pure nanocellulose. This lower WVTR is attributed to the hemicelluloses present in the PCA-L composition, which may show higher WVTR than nanocelluloses. ${ }^{64}$ In any case, WVTR values of the developed films were higher than the ones of $\mathrm{PLA}^{20}$ but lower than the major part of other hemicellulosic films. ${ }^{64}$ On the other hand, different trends were observed for the OTR values as a function of increasing nanocellulose percentage in both sets of films, presenting the best oxygen barrier properties for composites with $30 \%$ and $60 \%$ nanocelluloses in their formulation. These composite films displayed lower OTR values than the pure CNF 
films and other commercial packaging materials, such as PET and PLA. ${ }^{20,65-68}$

The antioxidant properties were investigated by calculating the onset temperature values of the different films from the DSC thermograms shown in Figure 4E. ${ }^{40}$ This technique has previously shown comparable results to the antioxidant properties evaluated via other techniques such as ABTS or DHPP. $^{22}$ In general, due to their higher lignin content, the LCNF films displayed higher onset values than the CNF films.

Table 1 shows the moisture uptake and mechanical properties of the films. It can be noted that both sets of CNF and LCNF films show similar water sorption; however, small differences may be noted. Pure CNF films show a slightly lower moisture uptake than pure LCNF films; however, the PCA-L/LCNF films displayed lower values than their corresponding PCA-L/CNF films. This finding may be due to the higher hydrophobicity and compatibility among the raw materials due to the higher percentage of lignin in the composite films.

In general, the LCNF composite films displayed better mechanical properties than the corresponding CNF composites films, probably due to the better compatibility between the reinforcement and the matrix due to the presence of lignin. Indeed, Espinosa et al. ${ }^{69}$ stated that nanofibrils containing lignin produce a higher specific surface area and binding reactions than CNF. Similar trends for the mechanical parameters in both sets of films were observed as a function of the increase of the nanocellulose load. For both types of nanocelluloses, the best mechanical properties were displayed by the films with $45 \%$ nanocellulose. PCA-L/CNF 45 and PCA-L/LCNF 45 had better tensile strength and tensile modulus than those corresponding values obtained for the pure nanocellulose films (CNF and LCNF, respectively). Reinforcement of PCA-L with $30 \%$ of nanocelluloses has shown to be enough to form coherent and homogeneous films (Figure 4A); however, the assessed mechanical properties were lower than those shown by their corresponding pure nanocellulose films. On the other hand, films with $60 \%$ of nanocelluloses have shown better mechanical performance than the films with $30 \%$ but worse than the films with $45 \%$ of nanocellulose. The highest amount of nanocelluloses in the formulations may show a higher tendency of the nanocelluloses to self-aggregate and, therefore, to reduce the interaction between matrix and reinforcement in the films. Among all the studied films, PCA-L/LCNF 45 showed the best mechanical properties and better tensile stress than PLA, with a value of around $50 \mathrm{MPa}$. 20,21

\section{CONCLUSIONS}

In the work, presented herein, pine cones, a forest and agro-food residue, were successfully valorized by a sequential integral biorefinery process into high-value-added composite films. The proposed biorefinery process allowed us to upgrade $57 \%$ of the initial residual biomass by the sequential recovery of two lignin/ hemicellulose-based fractions and two different cellulose-rich fractions. Cellulose nanofibrils with different lignin contents were produced (CNF and LCNF with $1 \%$ and $16 \%$ lignin, respectively) from the cellulose-rich fractions. Different amounts of CNF and LCNF were used as reinforcements of the first extracted lignin-based fraction to form composite films. The quality of the different nanocelluloses, the film-forming capability of different nanocellulose loads, and the film performance showed a clear dependence on the nanocellulose lignin content. A higher lignin content in nanocelluloses allowed us to obtain composite films with an enhanced compatibility between the matrix and the reinforcement, resulting in films with good barrier properties, antioxidant functionality, and improved thermomechanical properties. However, the CNF composite films showed better barrier properties than the LCNF composites. Therefore, the properties of the different films can be tailored by selecting the type and loading of nanocelluloses in the composite film formulation.

The proposed biorefinery process enables the valorization of low-value, abundant residual biomass into biobased films with high potential to be used as multifunctional food packaging materials due to their competitive thermomechanical, antioxidant, and barrier properties.

\section{ASSOCIATED CONTENT}

\section{sI Supporting Information}

The Supporting Information is available free of charge at https://pubs.acs.org/doi/10.1021/acssuschemeng.0c07687.

FTIR spectra of CNF, LCNF, PCAAC, and PCAAP used to calculate the cellulose crystallinity index (CrI) of all these samples (PDF)

\section{AUTHOR INFORMATION}

\section{Corresponding Author}

Rosana Moriana - Department of Fibre and Polymer Technology, School of Engineering Sciences in Chemistry, Biotechnology and Health, KTH-Royal Institute of Technology, 10044 Stockholm, Sweden; Department of Molecular Sciences, SLU-Swedish University of Agricultural Sciences, Uppsala, Sweden; Department of Bioeconomy and Health, RISE-Research Institutes of Sweden, Stockholm, Sweden; 10 orcid.org/0000-0002-0252-337X; Email: rosana.moriana.torro@ri.se,rosana@kth.se

\section{Authors}

Jon Trifol - Department of Fibre and Polymer Technology, School of Engineering Sciences in Chemistry, Biotechnology and Health, KTH-Royal Institute of Technology, 10044 Stockholm, Sweden; i orcid.org/0000-0001-9447-1089

Diana Catalina Marin Quintero - Department of Fibre and Polymer Technology, School of Engineering Sciences in Chemistry, Biotechnology and Health, KTH-Royal Institute of Technology, 10044 Stockholm, Sweden

Complete contact information is available at: https://pubs.acs.org/10.1021/acssuschemeng.0c07687

\section{Notes}

The authors declare no competing financial interest.

\section{ACKNOWLEDGMENTS}

This research was supported by ÅForsk, Project 18-316.

\section{REFERENCES}

(1) Cherubini, F.; Ulgiati, S. Crop Residues as Raw Materials for Biorefinery Systems - A LCA Case Study. Appl. Energy 2010, 87 (1), 47-57.

(2) Siles López, J. A.; Li, Q.; Thompson, I. P. Biorefinery of Waste Orange Peel. Crit. Rev. Biotechnol. 2010, 30 (1), 63-69.

(3) Liu, S.; Lu, H.; Hu, R.; Shupe, A.; Lin, L.; Liang, B. A Sustainable Woody Biomass Biorefinery. Biotechnol. Adv. 2012, 30 (4), 785-810.

(4) Svärd, A.; Moriana, R.; Brännvall, E.; Edlund, U. Rapeseed Straw Biorefinery Process. ACS Sustain. ACS Sustainable Chem. Eng. 2019, 7 (1), 790-801. 
(5) Kaparaju, P.; Serrano, M.; Thomsen, A. B.; Kongjan, P.; Angelidaki, I. Bioethanol, Biohydrogen and Biogas Production from Wheat Straw in a Biorefinery Concept. Bioresour. Technol. 2009, 100 (9), 2562-2568.

(6) Moriana, R.; Vilaplana, F.; Ek, M. Forest Residues as Renewable Resources for Bio-Based Polymeric Materials and Bioenergy: Chemical Composition, Structure and Thermal Properties. Cellulose 2015, 22 (5), 3409-3423.

(7) Ragauskas, A. J. The Path Forward for Biofuels and Biomaterials. Science (Washington, DC, U. S.) 2006, 311 (5760), 484-489.

(8) Cherubini, F. The Biorefinery Concept: Using Biomass Instead of Oil for Producing Energy and Chemicals. Energy Convers. Manage. 2010, 51 (7), 1412-1421.

(9) Forests, forestry and logging. Eurostat. https://ec.europa.eu/ eurostat/statistics-explained/index.php/Forests, forestry_and logging (accessed Jan 7, 2021).

(10) Buras, A.; Menzel, A. Projecting Tree Species Composition Changes of European Forests for 2061-2090 Under RCP 4.5 and RCP 8.5 Scenarios. Front. Plant Sci. 2019, 9, 1-13.

(11) Repo, A.; Känkänen, R.; Tuovinen, J. P.; Antikainen, R.; Tuomi, M.; Vanhala, P.; Liski, J. Forest Bioenergy Climate Impact Can Be Improved by Allocating Forest Residue Removal. GCB Bioenergy 2012, 4 (2), 202-212.

(12) Moriana, R.; Vilaplana, F.; Ek, M. Cellulose Nanocrystals from Forest Residues as Reinforcing Agents for Composites: A Study from Macro- to Nano-Dimensions. Carbohydr. Polym. 2016, 139, 139-149.

(13) Le Normand, M.; Moriana, R.; Ek, M. Isolation and Characterization of Cellulose Nanocrystals from Spruce Bark in a Biorefinery Perspective. Carbohydr. Polym. 2014, 111, 979-987.

(14) García-García, D.; Balart, R.; Lopez-Martinez, J.; Ek, M.; Moriana, R. Optimizing the Yield and Physico-Chemical Properties of Pine Cone Cellulose Nanocrystals by Different Hydrolysis Time. Cellulose 2018, 25 (5), 2925-2938.

(15) Pacheco, G.; Nogueira, C. R.; Meneguin, A. B.; Trovatti, E.; Silva, M. C. C.; Machado, R. T. A.; Ribeiro, S. J. L.; da Silva Filho, E. C.; da S. Barud, H. Development and Characterization of Bacterial Cellulose Produced by Cashew Tree Residues as Alternative Carbon Source. Ind. Crops Prod. 2017, 107, 13-19.

(16) Le Normand, M.; Moriana, R.; Ek, M. The Bark Biorefinery: A Side-Stream of the Forest Industry Converted into Nanocomposites with High Oxygen-Barrier Properties. Cellulose 2014, 21 (6), 45834594.

(17) Oinonen, P.; Krawczyk, H.; Ek, M.; Henriksson, G.; Moriana, R. Bioinspired Composites from Cross-Linked Galactoglucomannan and Microfibrillated Cellulose: Thermal, Mechanical and Oxygen Barrier Properties. Carbohydr. Polym. 2016, 136, 146-153.

(18) El-Wakil, N. A.; Hassan, E. A.; Abou-Zeid, R. E.; Dufresne, A. Development of Wheat Gluten/Nanocellulose/Titanium Dioxide Nanocomposites for Active Food Packaging. Carbohydr. Polym. 2015, 124, 337-346.

(19) Azeredo, H. M. C.; Rosa, M. F.; Mattoso, L. H. C. Nanocellulose in Bio-Based Food Packaging Applications. Ind. Crops Prod. 2017, 97, 664-671.

(20) Trifol, J.; Plackett, D.; Sillard, C.; Szabo, P.; Bras, J.; Daugaard, A. E. Hybrid Poly(Lactic Acid)/Nanocellulose/Nanoclay Composites with Synergistically Enhanced Barrier Properties and Improved Thermomechanical Resistance. Polym. Int. 2016, 65 (8), 988-995.

(21) Trifol, J.; Plackett, D.; Sillard, C.; Hassager, O.; Daugaard, A. E.; Bras, J.; Szabo, P. A Comparison of Partially Acetylated Nanocellulose, Nanocrystalline Cellulose, and Nanoclay as Fillers for High-Performance Polylactide Nanocomposites. J. Appl. Polym. Sci. 2016, 133 (14), $1-14$.

(22) Tagami, A.; Gioia, C.; Lauberts, M.; Budnyak, T.; Moriana, R.; Lindström, M. E.; Sevastyanova, O. Solvent Fractionation of Softwood and Hardwood Kraft Lignins for More Efficient Uses: Compositional, Structural, Thermal, Antioxidant and Adsorption Properties. Ind. Crops Prod. 2019, 129, 123-134.
(23) Abdul Khalil, H. P. S.; Issam, A. M.; Ahmad Shakri, M. T.; Suriani, R.; Awang, A. Y. Conventional Agro-Composites from Chemically Modified Fibres. Ind. Crops Prod. 2007, 26 (3), 315-323.

(24) Alzagameem; Klein; Bergs; Do; Korte; Dohlen; Hüwe; Kreyenschmidt; Kamm; Larkins; Schulze. Antimicrobial Activity of Lignin and Lignin-Derived Cellulose and Chitosan Composites Against Selected Pathogenic and Spoilage Microorganisms. Polymers 2019, 11 (4), 670.

(25) Mikkelsen, D.; Gidley, M. J. Formation of Cellulose-Based Composites with Hemicelluloses and Pectins Using Gluconacetobacter Fermentation. Methods Mol. Biol. 2011, 715, 197-208.

(26) Kalia, S., Ed.; Lignocellulosic Composite Materials; Springer Series on Polymer and Composite Materials; Springer International Publishing: Cham, 2018. DOI: 10.1007/978-3-319-68696-7.

(27) Chen, Y.; Zhao, H.; Liu, X.; Li, Z.; Liu, B.; Wu, J.; Shi, M.; Norde, W.; Li, Y. TEMPO-Oxidized Konjac Glucomannan as Appliance for the Preparation of Hard Capsules. Carbohydr. Polym. 2016, 143, 262-269.

(28) Ma, Y.; Lv, L.; Guo, Y.; Fu, Y.; Shao, Q.; Wu, T.; Guo, S.; Sun, K.; Guo, X.; Wujcik, E. K.; Guo, Z. Porous Lignin Based Poly (Acrylic Acid)/Organo-Montmorillonite Nanocomposites: Swelling Behaviors and Rapid Removal of $\mathrm{Pb}$ (II) Ions. Polymer 2017, 128, 12-23.

(29) Wang, X.; Han, G.; Shen, Z.; Sun, R. Fabrication, Property, and Application of Lignin-Based Nanocomposites. In Eco-friendly Polymer Nanocomposites: Chemistry and Applications; Thakur, V. K., Thakur, M. K., Eds.; Springer: New Delhi, India, 2015; pp 73-99. DOI: 10.1007/ 978-81-322-2473-0 3.

(30) Mutke, S.; Gordo, J.; Gil, L. Variability of Mediterranean Stone Pine Cone Production: Yield Loss as Response to Climate Change. Agric. For. Meteorol. 2005, 132 (3-4), 263-272.

(31) Exporting Pine Nuts to Europe. Centre for the Promotion of Imports from Developing Countries. https://www.cbi.eu/marketinformation/processed-fruit-vegetables-edible-nuts/pine-nuts (accessed Jan 7, 2021).

(32) Holm, A.; Niklasson, R. The Effect on Wood Components during Soda Pulping, M.Sc. Thesis, Chalmers University of Technology, Gothenburg, 2018.

(33) Lin, S. Y.; Dence, C. W., Eds.; Methods in Lignin Chemistry; Springer Series in Wood Science; Springer: Berlin, Heidelberg, 1992. DOI: 10.1007/978-3-642-74065-7.

(34) Trifol, J.; Sillard, C.; Plackett, D.; Szabo, P.; Bras, J.; Daugaard, A. E. Chemically Extracted Nanocellulose from Sisal Fibres by a Simple and Industrially Relevant Process. Cellulose 2017, 24 (1), 107-118.

(35) Moriana, R.; Zhang, Y.; Mischnick, P.; Li, J.; Ek, M. Thermal Degradation Behavior and Kinetic Analysis of Spruce Glucomannan and Its Methylated Derivatives. Carbohydr. Polym. 2014, 106 (1), 6070.

(36) Nelson, M. L.; O'Connor, R. T. Relation of Certain Infrared Bands to Cellulose Crystallinity and Crystal Lattice Type. Part II. A New Infrared Ratio for Estimation of Crystallinity in Celluloses I and II. J. Appl. Polym. Sci. 1964, 8 (3), 1325-1341.

(37) Segal, L.; Creely, J. J.; Martin, A. E.; Conrad, C. M. An Empirical Method for Estimating the Degree of Crystallinity of Native Cellulose Using the X-Ray Diffractometer. Text. Res. J. 1959, 29 (10), 786-794.

(38) Requena, R.; Jiménez-Quero, A.; Vargas, M.; Moriana, R.; Chiralt, A.; Vilaplana, F. Integral Fractionation of Rice Husks into Bioactive Arabinoxylans, Cellulose Nanocrystals, and Silica Particles. ACS Sustainable Chem. Eng. 2019, 7 (6), 6275-6286.

(39) Tsuji, H.; Okino, R.; Daimon, H.; Fujie, K. Water Vapor Permeability of Poly(Lactide)s: Effects of Molecular Characteristics and Crystallinity. J. Appl. Polym. Sci. 2006, 99 (5), 2245-2252.

(40) España, J. M.; Fages, E.; Moriana, R.; Boronat, T.; Balart, R. Antioxidant and Antibacterial Effects of Natural Phenolic Compounds on Green Composite Materials. Polym. Compos. 2012, 33 (8), 12881294.

(41) Edwards, M. C.; Doran-Peterson, J. Pectin-Rich Biomass as Feedstock for Fuel Ethanol Production. Appl. Microbiol. Biotechnol. 2012, 95 (3), 565-575.

(42) Rambabu, N.; Panthapulakkal, S.; Sain, M.; Dalai, A. K. Production of Nanocellulose Fibers from Pinecone Biomass: 
Evaluation and Optimization of Chemical and Mechanical Treatment Conditions on Mechanical Properties of Nanocellulose Films. Ind. Crops Prod. 2016, 83, 746-754.

(43) Gulsoy, S. K.; Ozturk, F. Kraft Pulping Properties of European Black Pine Cone. Maderas. Cienc. y Tecnol. 2015, 17 (4), 875-882.

(44) Micales, J. A.; Han, J. S.; Davis, J. L.; Young, R. A. Chemical Composition and Fungitoxic Activities of Pine Cone Extractives. In Mycotoxins, Wood Decay, Plant Stress, Biocorrosion, and General Biodeterioration; Springer: Boston, MA, 1994; pp 317-332. DOI: 10.1007/978-1-4757-9450-2_25.

(45) Xu, J.-K.; Sun, R.-C. Recent Advances in Alkaline Pretreatment of Lignocellulosic Biomass. In Biomass Fractionation Technologies for a Lignocellulosic Feedstock Based Biorefinery; Elsevier, 2016; pp 431-459. DOI: 10.1016/B978-0-12-802323-5.00019-0.

(46) Tolbert, A.; Akinosho, H.; Khunsupat, R.; Naskar, A. K.; Ragauskas, A. J. Characterization and Analysis of the Molecular Weight of Lignin for Biorefining Studies. Biofuels, Bioprod. Biorefin. 2014, 8 (6), $836-856$.

(47) Erdocia, X.; Prado, R.; Corcuera, M. Ã.; Labidi, J. Influence of Reaction Conditions on Lignin Hydrothermal Treatment. Front. Energy Res. 2014, 2 (April), 1-7.

(48) Song, K.; Chang, S. S.; Roper, M.; Kim, H.; Lee, S. J. A Biologically-Inspired Symmetric Bidirectional Switch. PLoS One 2017, 12 (1), e0169856.

(49) Ticoalu, A.; Aravinthan, T.; Cardona, F. A Review on the Characteristics of Gomuti Fibre and Its Composites with Thermoset Resins. J. Reinf. Plast. Compos. 2013, 32 (2), 124-136.

(50) Sable, I.; Grinfelds, U.; Jansons, A.; Vikele, L.; Irbe, I.; Verovkins, A.; Treimanis, A. Comparison of the Properties of Wood and Pulp Fibers from Lodgepole Pine (Pinus Contorta) and Scots Pine (Pinus Sylvestris). BioResources 2012, 7 (2), 1771-1783.

(51) Bufalino, L.; de Sena Neto, A. R.; Tonoli, G. H. D.; de Souza Fonseca, A.; Costa, T. G.; Marconcini, J. M.; Colodette, J. L.; Labory, C. R. G.; Mendes, L. M. How the Chemical Nature of Brazilian Hardwoods Affects Nanofibrillation of Cellulose Fibers and Film Optical Quality. Cellulose 2015, 22 (6), 3657-3672.

(52) Tarasov, D.; Leitch, M.; Fatehi, P. Lignin-Carbohydrate Complexes: Properties, Applications, Analyses, and Methods of Extraction: A Review. Biotechnol. Biofuels 2018, 11 (1), 1-28.

(53) Oriez, V.; Peydecastaing, J.; Pontalier, P.-Y. Lignocellulosic Biomass Mild Alkaline Fractionation and Resulting Extract Purification Processes: Conditions, Yields, and Purities. Clean Technol. 2020, 2 (1), 91-115.

(54) Chen, Y.; Zhang, L.; Yu, J.; Lu, Y.; Jiang, B.; Fan, Y.; Wang, Z. High-Purity Lignin Isolated from Poplar Wood Meal through Dissolving Treatment with Deep Eutectic Solvents. R. Soc. Open Sci. 2019, 6 (1), 181757.

(55) Chen, Y.; Fan, D.; Han, Y.; Lyu, S.; Lu, Y.; Li, G.; Jiang, F.; Wang, S. Effect of High Residual Lignin on the Properties of Cellulose Nanofibrils/Films. Cellulose 2018, 25 (11), 6421-6431.

(56) Park, C.-W.; Han, S.-Y.; Namgung, H.-W.; Seo, P.-n.; Lee, S.-Y.; Lee, S.-H. Preparation and Characterization of Cellulose Nanofibrils with Varying Chemical Compositions. BioResources 2017, 12 (3), 5031-5044.

(57) Peng, X.; Zhong, L.; Ren, J.; Sun, R. Laccase and Alkali Treatments of Cellulose Fibre: Surface Lignin and Its Influences on Fibre Surface Properties and Interfacial Behaviour of Sisal Fibre/ Phenolic Resin Composites. Composites, Part A 2010, 41 (12), 18481856.

(58) Lucenius, J.; Valle-Delgado, J. J.; Parikka, K.; Österberg, M. Understanding Hemicellulose-Cellulose Interactions in Cellulose Nanofibril-Based Composites. J. Colloid Interface Sci. 2019, 555, 104-114.

(59) Saelee, K.; Yingkamhaeng, N.; Nimchua, T.; Sukyai, P. An Environmentally Friendly Xylanase-Assisted Pretreatment for Cellulose Nanofibrils Isolation from Sugarcane Bagasse by High-Pressure Homogenization. Ind. Crops Prod. 2016, 82, 149-160.

(60) Bian, H.; Gao, Y.; Luo, J.; Jiao, L.; Wu, W.; Fang, G.; Dai, H. Lignocellulosic Nanofibrils Produced Using Wheat Straw and Their
Pulping Solid Residue: From Agricultural Waste to Cellulose Nanomaterials. Waste Manage. 2019, 91, 1-8.

(61) Abdulkhani, A.; Najd Mazhar, A.; Hedjazi, S.; Hamzeh, Y. Preparation of Xylan Bio-Composite Films Reinforced with Oxidized Carboxymethyl Cellulose and Nanocellulose. Polym. Bull. 2020, 77 (12), 6227-6239.

(62) Chaichi, M.; Hashemi, M.; Badii, F.; Mohammadi, A. Preparation and Characterization of a Novel Bionanocomposite Edible Film Based on Pectin and Crystalline Nanocellulose. Carbohydr. Polym. 2017, 157, $167-175$.

(63) Trifol, J.; Plackett, D.; Szabo, P.; Daugaard, A. E.; Giacinti Baschetti, M. Effect of Crystallinity on Water Vapor Sorption, Diffusion, and Permeation of PLA-Based Nanocomposites. ACS Omega 2020, 5 (25), 15362-15369.

(64) Sabiha-Hanim, S.; Siti-Norsafurah, A. M. Physical Properties of Hemicellulose Films from Sugarcane Bagasse. Procedia Eng. 2012, 42, 1390-1395.

(65) Liu, A.; Walther, A.; Ikkala, O.; Belova, L.; Berglund, L. A. Clay Nanopaper with Tough Cellulose Nanofiber Matrix for Fire Retardancy and Gas Barrier Functions. Biomacromolecules 2011, 12 (3), 633-641.

(66) Gas Barrier Properties. Mitsubishi Gas Chemicals. https://www. mgc.co.jp/eng/products/ac/nmxd6/barrier.html (accessed Jan 7, 2021).

(67) Nair, S. S.; Zhu, J.; Deng, Y.; Ragauskas, A. J. High Performance Green Barriers Based on Nanocellulose. Sustainable Chem. Processes 2014, 2 (1), 1-7.

(68) Logothetidis, S.; Laskarakis, A.; Georgiou, D.; Amberg-Schwab, S.; Weber, U.; Noller, K.; Schmidt, M.; Küçükpinar-Niarchos, E.; Lohwasser, W. Ultra High Barrier Materials for Encapsulation of Flexible Organic Electronics. Eur. Phys. J.: Appl. Phys. 2010, 51 (3), 33203.

(69) Espinosa, E.; Rol, F.; Bras, J.; Rodríguez, A. Use of MultiFactorial Analysis to Determine the Quality of Cellulose Nanofibers: Effect of Nanofibrillation Treatment and Residual Lignin Content. Cellulose 2020, 27, 10689. 